\title{
Somatic Embryogenesis in Juniperus Procera using Juniperus Communis as a Model
}

\author{
Seblework Belaineh \\ Institute of Biodiversity Conservation, P.O. Box 30726, Addis Ababa, Ethiopia \\ (bseblework@yahoo.com)
}

\begin{abstract}
The study of somatic embryogenesis in Juniperus communis has been conducted as a preliminary study for the further development of somatic embryogenesis, micropropagation and long-term conservation/cryopreservation in Juniperus procera, which is economically and ecologically important and endangered forest species in Ethiopia.

The aim for this particular research was initially an adaptation of optimum half strength lithium chloride-sodium propionate (LP) medium protocol for growth and proliferation of embryogenic culture. But as other conifer species it was difficult to stop proliferation of somatic embryo cell division and bring them to maturation stage. However using optimal concentration of ABA (32 $\mathrm{mg} / \mathrm{l})$, it was possible to get maturation response in most of the cultures.

Additional study on the effect of seed extraction to the growing embryogenic culture showed no effect on mature somatic embryos. Rather they were showing faster growth which increases embryogenic mass of each culture. It was also observed that green premature seeds of Juniperus are suitable for the initiation and proliferation of somatic embryo.
\end{abstract}

Key words: Cryopreservation, Juniperus communis, Juniperus procera, Somatic embryogenesis.

\section{INTRODUCTION}

Juniperus procera is an evergreen dioecious, more seldom monoecius tree, which belongs to the family Cupressaceae. It is the tallest/largest juniper tree in the world (Pohjonen and Pukkala, 1992; Negash, 1995). It has two developmental phases, the juvenile and the adult stage. They are characterized by their distinctive trunk and crown shapes. It has a pyramidal shape when it is young and more spreading when it gets older. It can reach up to $45 \mathrm{~m}$ high when it matures (Berhe and Negash, 1998). The male cones are small and round. They are borne individually and terminally on short branch lets. The female cones are berry-like rounded and, upon ripening, become fleshy and soft (Negash, 1995). Juniper trees flower and give fruits through out the year in Ethiopia without an interrupting resting stage (Achalu, 1995).

J. procera is the only Juniperus species, which is found in the mountains of East Africa and it is one of the two indigenous conifer species found in Ethiopia (Pohjonen and Pukkala, 1992). Locally it is known as Tid and commercially as African Pencil Cedar. It is naturally found in the 
central highlands of the country, mainly between altitudes 1800-3200 meters above sea level (von Breitenbach, 1963) with an annual rainfall range that varies between 450 and 1200 millimetres (Jansen, 1981). The optimum altitude range, however, is between 2200 and 2500 meters above sea level (Pohjonen and Pukkala, 1992). It is found in montane vegetation as the dominant species or mixed with other evergreen forests. It grows well in drier climatic zones.

J. procera has been a very important source of wood for timber and fuel. Its wood is fragrant, fine-textured, and strait-grained. It is hardy and resistant to termites and fungal diseases. Because of these distinctive qualities, it is highly valued for the construction of houses, internal structures of churches, furniture and for poles (Achalu, 1995; Negash, 1995). The tree is planted as ornamental and for its shade in homesteads. Its fruits have also some medicinal values for curing headaches, skin diseases etc. Its resin in combination with honey is used as stimulant and as a medicine against ulcers as well as against liver diseases (Jansen, 1981; von Arnold et al., 2005). Juniperus species have therefore become important in long term rehabilitation projects. The natural habitat of several Juniperus species has been greatly reduced because of overexploitation for timber and fuel wood and clearance for cultivation. Furthermore, several species belonging to the genus Juniperus are hard to propagate via seeds (Ortiz et al., 1998; Helmersson and von Arnold, 2009). The possibility to propagate trees vegetatively creates significant advantages both for the deployment of selected genotypes through mass propagation and for capturing and enhancing genetic gain in breeding programs. Large scale cutting propagation is limited in several coniferous species owing to problems with rooting, aging of mother trees and high costs. Some of these problems can be overcome by using somatic embryos. Somatic embryogenesis has been described in several coniferous species and especially species belonging to the Pinaceae family e.g. Abies, Larix, Picea and Pinus. However, reports from the Cupressaceae family are scarce. Up to now there is only one report showing that it is possible to produce somatic embryos in Juniperus (J. oxycedrus), however, no mature somatic embryos or plants were obtained. We have chosen common juniper, Juniperus communis, as a model species for $J$. procera for studying possibilities and limitations with somatic embryogenesis (Gomez and Segura, 1996; Helmersson and von Arnold, 2009).

This study is carried out on J. procera, as a multipurpose tree, because of its use as a good alternative to the exotic species for reforestation and its drought tolerant, easily adaptability and importance for soil and water conservation. Furthermore, the rapid disappearance of this 
endogenous and very important tree from its natural habitats is another argument for the development of Somatic embryogenesis.

\section{MATERIALS}

\subsection{Seed samples}

$200 \mathrm{~J}$. communis from Uppsala Genetic Center and 200 embryo seeds of J. Procera from Menagesha Suba forest in Ethiopia were use for analysis of this study.

\subsection{Culture medium}

Half strength lithium chloride-sodium propionate (LP)-medium containing $15 \mathrm{~mm} \mathrm{NH}_{4} \mathrm{NO}_{3}$ (Merck), $30 \mathrm{~mm}$ sucrose (BDH), $9.0 \mu \mathrm{m}, 2,4-$ dichlorophenoxyacetic acid (2,4-D) (Sigma) and $4.4 \mu \mathrm{m}$ N6-benzyladenine (BA) (Sigma), solidified with 0.4\% gellan gum (Merck) was used (von Arnold and Eriksson, 1981; Hakan, 1996). Cryopreservation medium -5\% DSMO were used for short and long term cropyopreservation of J. Procera.

\section{METHODS}

\subsection{Seed collection}

$200 \mathrm{~J}$. communis seeds were collected from Uppsala Genetic Center from January to February 2005 and 200 mature, healthy, deep green color and soft look embryo seeds of J. Procera were collected from Menagesha Suba forest in Ethiopia from March to April 2004. Seed were collected randomly to get 200 green seeds for initial work of analysis over all.

\subsection{Seed sterilization}

Premature green seeds were carefully pressed in a mortar by a pistol, and separate seeds from the seed cots and the debris by washing them on a colander under the tap water. Care was taken not to damage the seeds when grinding them by a mortar. Seeds were surface sterilized in $10 \%$ (w/v), sodium hypochloride with two drops of Tween 20 and left on a rotary shaker for 20 minutes to make sure that all seeds are cleaned and washed. The solution was removed and the seeds were washed using $70 \%$ ethanol for 1 minute. Then they were rinsed three times with sterile distilled water and incubated over night in a small amount of sterile distilled water at $4^{\circ} \mathrm{C}$.

\subsection{Half LP medium preparation}

Half LP liquid medium contains $30 \mathrm{mM}(10 \mathrm{mg} / \mathrm{l})$ sucrose and $0.44 \mathrm{gm} / \mathrm{l}$ filter sterilized LGlutamine. The $\mathrm{pH}$ was adjusted to $5.8 \pm 0.01$ after adjusting it to the required volume. L- 
glutamine was added to the medium after autoclaving the medium on $121^{\circ} \mathrm{C}$ for 20 minutes under the pressure of $0.3 \mathrm{~atm}$. It is very important to wait until the media cools down to $35-40^{\circ} \mathrm{C}$ before adding the L-glutamine.

\subsection{Mega gametophytes Preparation}

Isolation work was done with the help of magnifier placed in a flow hood and by placing the seeds on sterile empty Petri dices. All equipment were sterilized and cooled before every application on the mega gametophyte all work was done under aseptic condition.

Seeds were opened with a scalpel and mega gametophytes were removed carefully with forceps, plated on a Petri dish containing LP half strength media which contain no hormones. 6-10 mega gametophytes were put in one $9 \mathrm{~cm}$ Petri dishes, closed tightly by para film or any plastic foil. When there was a doubt for viability, viability test was done before plating them in the growth media. The cultures were incubated at $+22^{\circ} \mathrm{C}$ in the dark. They were sub cultured every three weeks to a freshly prepared 0.5 LP medium.

Mature embryos from seeds of J. procera were inoculated on PGR containing LP medium. It was hard to open each seed and get the mature embryo with out any damage. Taking out the mature embryo procedures are all the same as premature green seeds of J. Communis. Sub culturing was done every month.

\subsection{Induction of embryogenic cultures}

Seeds were removed from the cones and surface sterilized in $70 \%$ ethanol (2 min), and 2\% sodium hipoclorite (10 min), followed by rinsing three times with sterile water. Explants were dominant and non-dominant zygotic embryos excised from immature seeds under a stereoscope and inoculated in Petri dishes $(100 \times 15 \mathrm{~mm})$ containing $20 \mathrm{~mL}$ of culture medium free of growth regulators $\left(\mathrm{LP}_{0}\right)$. The cultures were incubated in the dark at $22 \pm 2{ }^{0} \mathrm{C}$. After 24 hours magagametophytes were cultured with nine zygotic embryos on freshly prepared media.

\subsection{Tracking}

Tracking medium used was 0.5 LP followed by $1.2 \%(\mathrm{w} / \mathrm{v})$ sea plaque agarose and following by $1.32 \mathrm{gm} / \mathrm{l}$ glutamine, after autoclaving the media. Sea plaque agarose is very transparent enabling to see the cell structure under the microscope. The selected well growing cell lines were taken from a suspension culture and left to settle down to the bottom of the jar for a while. Then using a sterile glass pipette and automatic pipette $1.5 \mathrm{ml}$ of liquid half LP medium was sucked to a $6 \mathrm{~mm}$ Petri dish and the same amount of cells to the Petri dish and waited until the cell gets in 
to the medium. Then to avoid contamination the Petri dishes were sealed by Para film. These were kept in the dark on $22^{\circ} \mathrm{C}$ for to grow.

\subsection{Maturation of somatic embryos}

In order to see the morphology of the embryo culture of J. procera, different concentration of (ABA) were applied on 15 lines (1, 2, 3, 17, 20, 24, 33, 37, 43, 44, 47, 50, 51, 52, 53) from earlier selection: $16 \mathrm{mg} / \mathrm{l}, 32 \mathrm{mg} / \mathrm{l}, 64 \mathrm{mg} / \mathrm{l}, 128 \mathrm{mg} / \mathrm{and} 256 \mathrm{mg} / \mathrm{l}$ per one liter of half LP

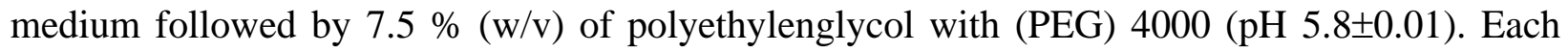
concentration trial was conducted in three replications.

\subsection{Cryopreservation}

4gm of the best performing cell line was taken after 14 days of the last subculture and transferred to $10 \mathrm{ml}$ half LP liquid medium and pumped carefully. Then the liquid medium was distributed in to 10 cryotubes.

On the first day, the culture in each cryotube was treated by $0.210 \mathrm{~mL}$ freshly prepared $4 \mathrm{M}$ sorbitol ten times over a period of 30 minutes and incubated on a rotary shaker with $100 \mathrm{rpm}$ over night at room temperature in the dark for 24 hours. The same procedure was repeated on the second and third day by adding $0.234 \mathrm{~mL}$ of $4 \mathrm{M}$ sorbitol.

After the third application of $4 \mathrm{M}$ sorbitol the cryotubes were placed on ice bath, and then the excessive LP medium was removed. The Tubes were labeled with necessary information and placed them to cryo box which is usable for preservation in liquid nitrogen, at $-196^{\circ} \mathrm{C}$ for two weeks. Thawing was beeing done by placing the cryotubes in distilled and sterile water at $45^{0} \mathrm{C}$ for 4 minutes, then transferred to $4^{\circ} \mathrm{C}$ for one minute. After this, the tubes were transferred to $70 \%$ ethanol for one minute, and then they were ready as a liquid medium suspended culture for further use.

\section{RESULT}

\subsection{Isolation and culture of embryos}

Both J. communis and J. Procera seeds were isolated on semi solid LP medium. 145 of $J$. communis and 67 of $J$. Procera seeds showed growth. All these seeds were cultured on fresh LP media every 21 days consequently three times after the first culturing. Growth of both species cell lines was compared. The growth of J. Communis was embryogenic, while the growth $J$. 
procera was non-embryogenic. Then best performing 53 non-embryogenic cell lines of $J$. Procera were taken for further characterization.
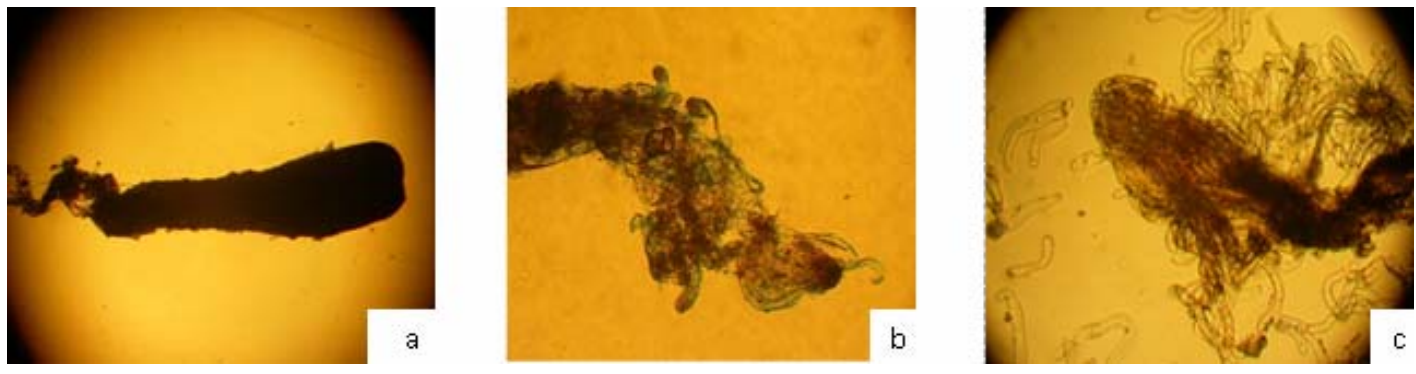

Figure 1. Formation of mega gametophytes of J. Procera, a) Full mega gametophyte (b) An embryo going out of the mega gametophyte (c) Several embryos following one big embryo.
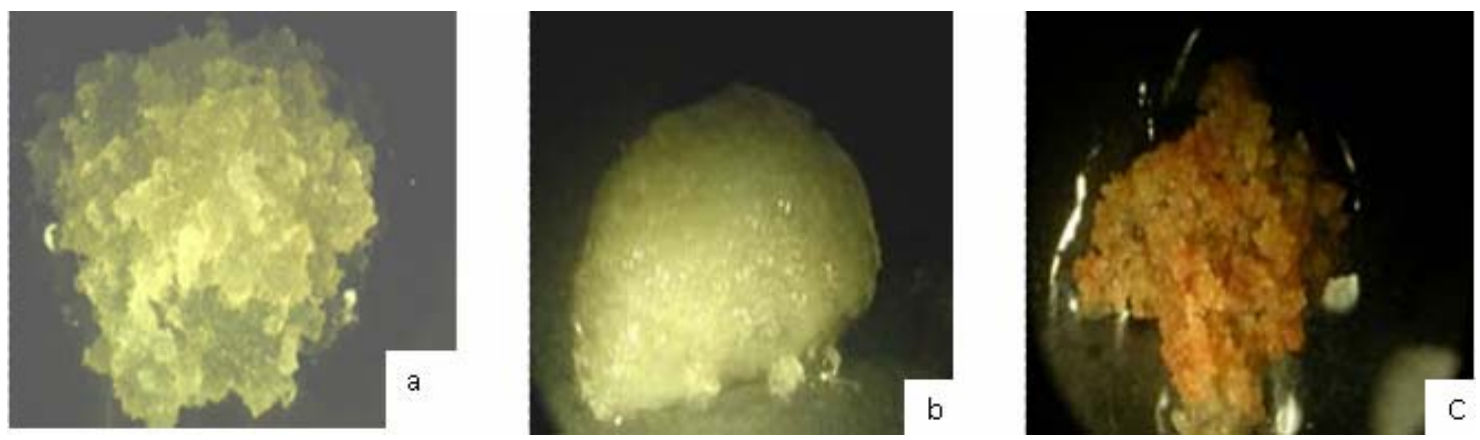

Figure 2. Morphotypes of non- embryogenic cell lines of J. procera, (a) Spiky granular (b) smooth (c) cell necrosis

\subsection{Characterization of non embryogenic cultures}

53 non-embryogenic cell-lines of $J$. Procera grown on semi solid medium differed in embryo morphology and growth habit, and were accordingly be divided into $\mathbf{A}, \mathbf{B}, \mathbf{C}$ and $\mathbf{D}$ for nonembryogenic morphotypes and $\mathbf{A}, \mathbf{B}$ and $\mathbf{C}$ for growth quality and callus colours, and (absence) or + (presence) for necrotizing cells (Table 1). 53 non embryogenic cell lines gave rise to proliferating non-embryogenic culture (Fig. 1). They were all transparent. 
Table 1. Characterization of embryos: morphology and growth habit.

\begin{tabular}{|c|c|c|c|c|c|}
\hline $\begin{array}{l}\text { No of } \\
\text { lines }\end{array}$ & $\begin{array}{c}\text { Non-embryogenic } \\
\text { morphotypes }\end{array}$ & Growth quality & $\begin{array}{l}\text { Growth habit } \\
\text { Callus colour }\end{array}$ & Necrosis cells & $\begin{array}{c}\text { Selected for } \\
\text { cryopreservation }\end{array}$ \\
\hline 1. & B & B & B & - & \\
\hline 2. & B & A & B & - & \\
\hline 3. & A & A & A & - & $\sqrt{ }$ \\
\hline 4. & C & A & B & - & \\
\hline 5. & C & A & B & - & \\
\hline 6. & D & B & C & + & \\
\hline 7. & C & B & A & - & \\
\hline 8. & C & B & A & - & \\
\hline 9. & D & C & A & - & \\
\hline 10. & D & A & C & + & \\
\hline 11. & B & A & C & + & \\
\hline 12. & D & A & B & - & \\
\hline 13. & D & A & C & + & \\
\hline 14. & C & A & A & - & \\
\hline 15. & D & B & C & + & \\
\hline 16. & C & A & A & - & \\
\hline 17. & A & A & B & - & $\sqrt{ }$ \\
\hline 18. & C & A & B & - & \\
\hline 19. & D & C & C & + & \\
\hline 20. & A & A & B & - & $\sqrt{ }$ \\
\hline 21. & D & C & A & - & \\
\hline 22. & C & B & B & - & \\
\hline 23. & C & A & A & - & \\
\hline 24. & A & A & A & - & $\sqrt{ }$ \\
\hline 25. & C & A & B & + & \\
\hline 26. & D & C & B & + & \\
\hline 27. & C & A & $\mathrm{C}$ & + & \\
\hline 28. & C & A & B & + & \\
\hline 29. & C & A & B & + & \\
\hline 30. & B & A & B & + & \\
\hline 31. & D & B & B & + & \\
\hline 32. & D & B & A & + & \\
\hline 33. & B & A & A & - & \\
\hline 34. & D & C & B & + & \\
\hline 35. & A & A & B & + & \\
\hline 36. & D & C & B & + & \\
\hline 37. & B & A & A & - & \\
\hline 38. & D & B & A & - & \\
\hline 39. & C & A & A & - & \\
\hline 40. & D & C & A & - & \\
\hline 41. & D & A & A & - & \\
\hline 42. & A & A & A & + & \\
\hline 43. & B & A & B & - & \\
\hline 44. & A & A & A & - & $\sqrt{ }$ \\
\hline 45. & D & A & A & - & \\
\hline 46. & D & A & A & - & \\
\hline 47. & A & A & A & - & $\sqrt{ }$ \\
\hline 48. & B & A & A & + & \\
\hline 49. & D & A & A & - & \\
\hline 50. & A & C & A & - & $\sqrt{ }$ \\
\hline 51. & A & A & A & - & $\sqrt{ }$ \\
\hline 52. & A & A & A & - & $\sqrt{ }$ \\
\hline 53. & A & A & A & - & $\sqrt{ }$ \\
\hline
\end{tabular}

Embryogenic morphotype: $\mathrm{A}=$ spiky, $\mathrm{B}=$ granular/spiky, $\mathrm{C}=$ granular, $\mathrm{D}=$ smooth, Necrosis cells: + = necrosis, $-=$ no necrosis; Growth quality: $\mathrm{A}=$ excellent, $\mathrm{B}=$ good, $\mathrm{C}=$ no growth; Callus colour: $\mathrm{A}=$ White, $\mathrm{B}=$ white/yellow, $\mathrm{C}=$ brown, 
Table 2. Maturation of embryos on ABA for cryopreservation.

\begin{tabular}{|c|c|c|c|c|}
\hline $\begin{array}{l}\text { No of } \\
\text { selected cell } \\
\text { lines }\end{array}$ & $\begin{array}{c}\text { ABA } \\
\text { concentration }\end{array}$ & $\begin{array}{l}\text { Growth } \\
\text { quality }\end{array}$ & $\begin{array}{l}\text { Type of organization } \\
\text { in somatic embryos }\end{array}$ & morphology \\
\hline \multirow[t]{3}{*}{3} & 128 & A & A & spiky \\
\hline & 32 & B & A & spiky \\
\hline & 64 & A & A & spiky \\
\hline \multirow[t]{3}{*}{17} & 128 & A & A & spiky \\
\hline & 32 & B & A & spiky \\
\hline & 64 & A & A & Spiky \\
\hline \multirow[t]{3}{*}{20} & 32 & A & A & Spiky \\
\hline & 64 & A & A & Spiky \\
\hline & 128 & B & A & Granular spiky \\
\hline \multirow[t]{3}{*}{24} & 32 & C & B & Granular spiky \\
\hline & 64 & $\mathrm{C}$ & B & Granular spiky \\
\hline & 128 & $\mathrm{C}$ & B & Granular spiky \\
\hline \multirow[t]{3}{*}{44} & 32 & A & A & spiky \\
\hline & 64 & A & A & spiky \\
\hline & 128 & B & A & Granular spiky \\
\hline \multirow[t]{3}{*}{47} & 32 & A & A & spiky \\
\hline & 64 & A & A & spiky \\
\hline & 128 & A & A & spiky \\
\hline \multirow[t]{3}{*}{50} & 32 & A & B & spiky \\
\hline & 64 & A & B & spiky \\
\hline & 128 & A & B & spiky \\
\hline \multirow[t]{3}{*}{51} & 32 & A & B & spiky \\
\hline & 64 & A & B & spiky \\
\hline & 128 & A & B & spiky \\
\hline \multirow[t]{3}{*}{52} & 32 & A & B & spiky \\
\hline & 64 & A & A & spiky \\
\hline & 128 & A & A & spiky \\
\hline \multirow[t]{3}{*}{53} & 32 & A & A & spiky \\
\hline & 64 & A & A & spiky \\
\hline & 128 & A & A & spiky \\
\hline
\end{tabular}

Growth quality: $\mathrm{A}=$ excellent, $\mathrm{B}=$ good, $\mathrm{C}=$ no growth; Callus colour: $\mathrm{A}=$ White, $\mathrm{B}=$ white/yellow, $\mathrm{C}=$ brown, Embryogenic morphotype: $\mathrm{A}=$ spiky, $\mathrm{B}=$ granular/spiky, $\mathrm{C}=$ granular, D = smooth, Necrosis cells: + = necrosis, $-=$ no necrosis

under electro microscope (Fig. 2). Non-embryogenic cultures derived from each mega gametophyte having a specific genotype were given cell line number. There were differences in morphotypes, growth rate, callus colour, and absences/presence of necrosis of cells in the cultures (Table 1). Out of 53 cell lines 15 were defined as spiky or granular/spiky with excellent to good growth quality, white to white/yellow callus color and with out necrosis (Table 1). Spiky cell are cells having the highest potential to differentiate further.

\subsection{Adaption for cryopreservation}

Out of 15 non-embryogenic fast growing, lacking necrosis cell lines 10 cell lines with best nonembryogenic morphotypes were tested for short and long term cryopreservation. For each line 
10 cryotubes were used. Two tubes from each culture were thawed after three weeks. 8 nonembryogenic cell lines showed excellent growth on half LP liquid medium incubated on $22^{\circ} \mathrm{C}$ for 24 hours (Table2).

\section{DISCUSSION}

The morphology of the somatic embryos $J$. communis was similar with in each cell line of $J$. procera.

Somatic embryos of $J$. communis are used as a model system in embryologic/non-embryogenic studies. However, the greatest importance of somatic embryos is its practical application in large scale vegetative propagation. In some cases, somatic embryogenesis is favoured over other methods of vegetative propagation because of the possibility to scale up the propagation by using bioreactors. In addition, in most cases the somatic embryos or the embryogenic cultures can be cryopreserved, which make it possible to establish GeneBank. Embryogenic cultures are also an attractive target for genetic modification (von Arnold et al., 2002).

In order to compare the morphology of the embryogenic culture model of J. communis and nonembryogenic culture of J. procera, different concentration of ABA were applied on 15 lines of $J$. procera. Both showed the best growth on ABA except the one is embryogenic and the other which was non-embryogenic.

During this work, the only difference was that $J$. communis is embryogenic with much faster growth, while J. procera is non-embryogenic with slow growth. That was the reason why 53 lines were performed better growth out of 200 premature green seeds of J. procera.

Out of morphologically identified 53 lines only 10 were perceived to grow better on ABA with spiky or granular spiky. These excellent cell lines showed good performance by having white and white- yellowish callus colour and with out necrosis.

Cell lines of $J$. procera with excellent morphotypes and maturation on ABA were used for further propagation and cryopreservation for- long and short- term conservation (Table.2).

Thus, those 10 excellent cell lines were tested for cryopreservation and 8 morphotypes of $J$. procera were showed excellent recovery response on half $\mathrm{LP}_{0}$ semi solid medium after three weeks cryopreservation at $-196^{\circ} \mathrm{C}$ liquid nitrogen. 


\section{CONCLUSION}

This study indicated the possible application of tissue culturing technique for conservation of forest tree species. In this particular case, since it is not a problem to get a green premature seeds of $J$. procera all year round, we recommend to use only the premature green seeds for the initiation and proliferation of somatic embryo. By using premature green seeds which gave mass of non-embryogenic cells, it might be possible to bring them to maturation by using the appropriate concentration of ABA, which is going to be useful for micropropagation and further studies on cryopreservation of this species.

\section{ACKNOWLEDGMENT}

This research was supported by SIDA/SAREC and the Department of Plant Biology and Forest Genetics (SLU). I would also like to thank Dr. Sara von Arnold’s research group and especially Dr. Sara von Arnold, Anna Lindström, David Clamps and Dr. Genene Tefera for his kindly support during my work and review ,last but not list my dear friend Eleni Shiferawu.

\section{REFERENCES}

Achalu, N. 1995. Monographic review on Juniperus excelsa. Alemaya University of Agriculture, Faculty of Forestry, 4 p.

Azene, B., Birnie. A \& Tengns, B. 1993. Useful.trees and shrubs Ethiopia: Identification Propagation, Management for Agricultural and Pastoral Communities. Technical Handbook No. 5, Regional Conservation Unit, Swedish International Development Authority (SIDA).

Berhe, B \& Negash, L. 1998. Asexual propagation of Juniperus procera from Ethiopia: a contribution to the conservation of African pencil cedar. Forest Ecology and Management, 112:179-190.

Egertsdotter, U \& von Arnold, S. 1995. Importance of arabinogalactan proteins for the development of somatic embryo of Norway spruce (Picea abies). Physiol. plant, 93:334345.

Håkan Mo, L., Egertsdotter, U \& von Arnold, S. 1996. Secretion of specific extracellular proteins by somatic embryos of Picea abies is dependent on embryo morphology. Annals of Botany, 77: 43-152. 
Helmersson, A \& von Arnold, S. 2009. Embryogenic cell lines of Juniperus communis; easy establishment and embryo maturation, limited germination. Plant cell, Tissue and Organ culture, 96:211-217.

Kartha, K. K \& Engelmann, F. 1994. Cryopreservation and germplasm storage. In: Vasil, I.K \& Thrope, T.A. (eds), Plant Cell And Tissue Culture, Klwver Academic publishers, pp.195230.

Negash, L.1995. Indigenous trees of Ethiopia Biolog, uses, and propagation techniques. Swedish University of Agriculture, Umea, p 231.

Ortiz, P.L., Arista, M \& Talavera, S. 1998. Low reproductive success in two subspecies of Juniperus Oxycedrus L. International Journal of Plant Science,159: 843-847.

Pohjonen, V \& Pukkala, T. 1992. Juniperus procera Hocht. ex Endl. in Ethiopian forestry. Forest Ecology and Management, 49:75-85.

Scofort, W.R. 1984. Genetic variability in tissue culture: Impact on Germplasm conservation and utilization. IBPGR, Rome.

von Arnold, S \& Eriksson, T. 1981. In vitro studies of adventitious shoot formation in Pinus contorta. Canadian Journal of Botany, 59: 870-874.

von Arnold, S., Izabela, S., Bozchkov, P., Dyachok, J \& Filonova, L. 2002. Developmental pathways of somatic embryogenesis. Plant cell, Tissue and Organ culture, 69: 233-249

von Arnold, S \& Springer, S. 2005. Liquid culture system for in-vitro plant propagation, p.588.

von Breitenbach, F. 1963. The indigenous Trees of Ethiopia (2nd ed). Ethiopian Forestry Association, Addis Ababa, Ethiopia, p. 305.

Withers, L.A. 1980. Tissue culture storage for genetic conservation. IBPGR, Tech Report, FAO, Rome. 